\section{SANDIA REPORT}

SAND95-1244 - UC-900

Unlimited Release

Printed June 1995
E

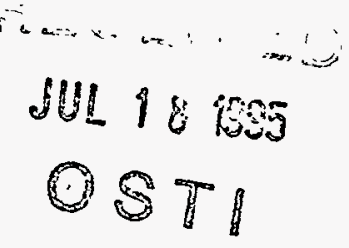

\title{
Team Learning Center Design Principles
}

Dr. Bonnie Daily, Dr. John Loveland, Dr. Arthur Whatley, Dr. Charles M. Tapp

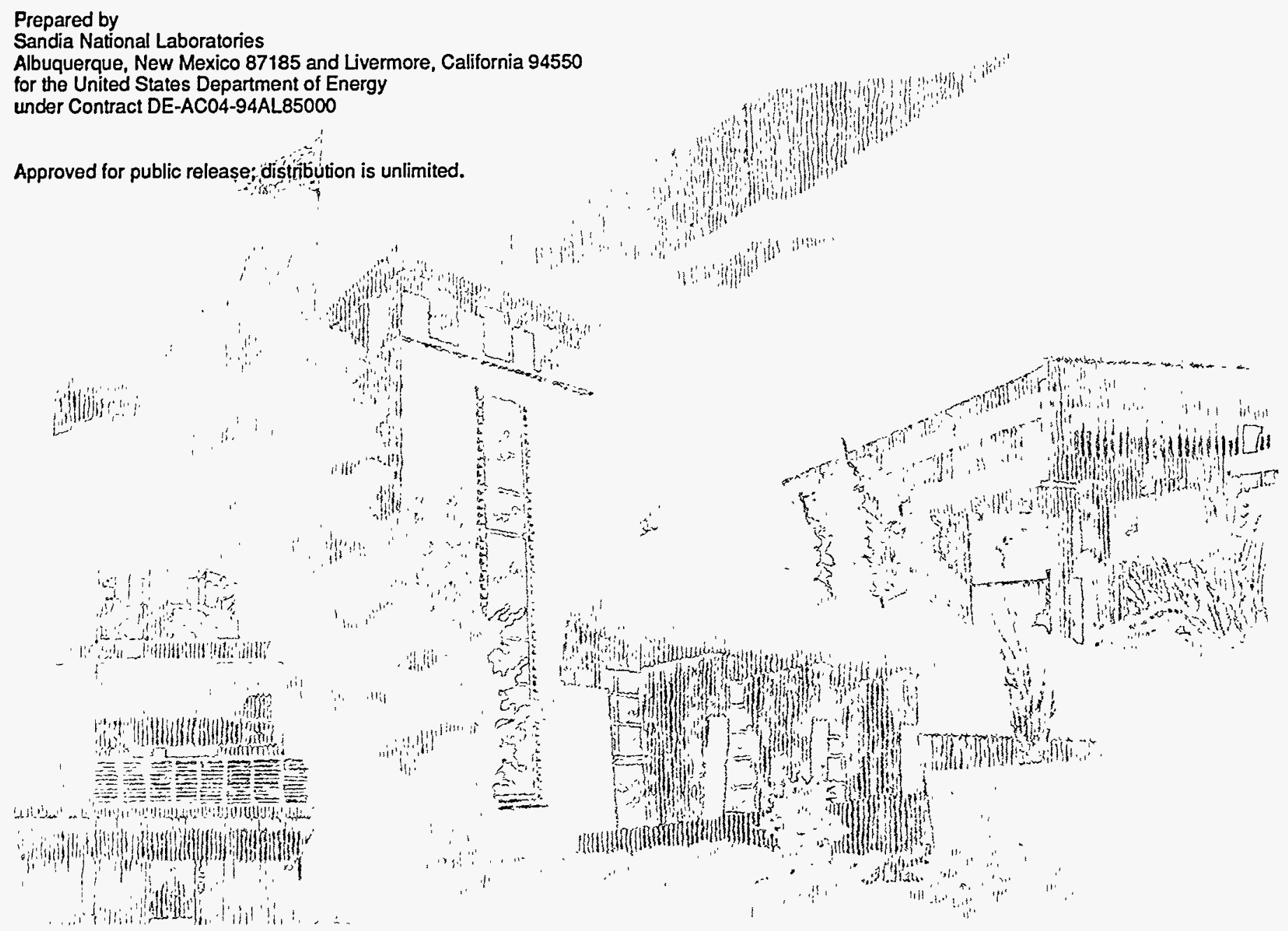


Issued by Sandia National Laboratories, operated for the United States Department of Energy by Sandia Corporation.

NOTICE: This report was prepared as an account of work sponsored by an agency of the United States Government. Neither the United States Government nor any agency thereof, nor any of their employees, nor any of their contractors, subcontractors, or their employees, makes any warranty, express or implied, or assumes any legal liability or responsibility for the accuracy, completeness, or usefulness of any information, apparatus, product, or process disclosed, or represents that its use would not infringe privately owned rights. Reference herein to any specific commercial product, process, or service by trade name, trademark, manufacturer, or otherwise, does not necessarily constitute or imply its endorsement, recommendation, or favoring by the United States Government, any agency thereof or any of their contractors or subcontractors. The views and opinions expressed herein do not necessarily state or reflect those of the United States Government, any agency thereof or any of their contractors.

Printed in the United States of America. This report has been reproduced directly from the best available copy.

Available to DOE and DOE contractors from Office of Scientific and Technical Information

PO Box 62

Oak Ridge, TN 37831

Prices available from (615) 576-8401, FTS 626-8401

Available to the public from

National Technical Information Service

US Department of Commerce

5285 Port Royal Rd

Springfield, VA 22161

NTIS price codes

Printed copy: A03

Microfiche copy: A01 


\section{DISCLAIMER}

Portions of this document may be illegible in electronic image products. Images are produced from the best available original document. 
Distribution

Category UC-900

SAND95-1244

Unlimited Distribution

Printed June 1995

\title{
Team Learning Center Design Principles
}

\author{
Dr. Bonnie Daily \\ Dr. John Loveland \\ Dr. Arthur Whatley \\ Department of Management \\ School of Business Administration and Economics \\ New Mexico State University \\ Las Cruces, NM 88003 \\ Dr. Charles M. Tapp \\ Quality Improvement Center \\ Sandia National Laboratories \\ Albuquerque, NM 87185-1369
}

\begin{abstract}
This is a preliminary report of a multi-year collaboration of the authors addressing the subject: Can a facility be designed for team learning and would it improve the efficiency and effectiveness of team interactions? Team learning in this context is a broad definition that covers all activities where small to large groups of people come together to work, to learn, and to share through team activities. Multimedia, networking, such as World Wide Web and other tools, are greatly enhancing the capability of individual learning. This paper addresses the application of technology and design to facilitate group or team learning. Many organizational meetings need tens of people to come together to do work as a large group and then divide into smaller subgroups of five to ten to work and then to return and report and interact with the larger group. Current facilities were not, in general, designed for this type of meeting. Problems with current facilities are defined and a preliminary design solution to many of the identified problems is presented.
\end{abstract}


(This page intentionally left blank) 


\section{Contents}

Section I. Data Collection Method.............................................................1

Section II. Data Summary......................................................................2

Problems.........................................................................2

Section III. Features of a Team Learning Center..........................................3

Desires for the Physical Site....................................................3

Desires of the Technology.....................................................5

General Philosophical Observations........................................5

Characteristics of the Center...................................................5

Appendix A - List of Attendees...........................................................

Appendix B - List of Problems..............................................................

Appendix C - Summary of Comments (Part 1).......................................

- Summary of Comments (Part 2).................................. 13 


\section{List of Figures}

Figure 1. Chairs must be flexible, roomy and comfortable for long periods.............6

Figure 2. Small groups are planned for two to ten per unit, with the actual..............7

- size determined by the facilitator or group. Units can be combined.

Figure 3. The center of the room is a raised, 10 -foot diameter platform...................8 surrounded by a circle of five of the tables (two-ten seats per table.

Figure 4. Another circle of eleven tables provides for a total capacity of..................9 160 seats. Radial partitions provide the flexibility to divide into groups of various sizes quickly, and resize the room as issues or needs change. 


\section{Team Learning Center Design Principles}

\section{Introduction}

This is a preliminary report of a multi-year collaboration of the authors addressing the subject: Can a facility be designed from first principles for team learning and would it improve the efficiency and effectiveness of team interactions and learning? Team learning in this context is a broad definition that covers all activities where small to large groups of people come together to work, to learn, and to share through team activities. Multimedia, networking, such as World Wide Web and other tools, are greatly enhancing the capability of individual learning. This paper addresses the application of current technology and design to facilitate group or team learning. The nature of many meetings has changed over the last decade. There is a wide-spread appreciation that many of today's problems and issues are so complex and

dynamic that a diversity of input is needed to develop an optimum solution. Few organizations can meet the challenge of today's rapidly changing times by relying on a hierarchical structure where the wisdom is in management and the work is done by workers. Successful institutions are utilizing full capabilities of all members of their organizations, focusing on their customer and stakeholder requirements, continuously improving their processes to increase customer delight and success. This approach to human interactions leads to:

- An increased number of meetings

- Meetings involving larger numbers of people, dozens to hundreds

- Meetings that have both large and small group activities sequentially

The authors have not been able to identify facilities that have been designed specifically to support these new kinds of meetings. In fact, most meetings have to work around the limitations of existing facilities, reducing their efficiency and productivity, rather than having a facility that synergistically could improve the productivity of the meeting.

\section{Data Collection Method}

In addition to a literature search reported elsewhere, the authors invited a group of participants from various colleges, schools and departments at New Mexico State University to convene to address the principles of designing a learning center. The attendees are listed in Appendix A. The group was asked to use laptop computers networked together and utilize GroupWare software to provide input. The group defined first the problems they had encountered in existing facilities and conference rooms and then were asked to provide input on the characteristics of a learning center specifically designed to promote team learning. 


\section{Data Summary}

\section{Problems}

The group generated a list of 63 problems in approximately ten minutes of input time, illustrating the power of GroupWare software and hardware to collect brainstorming kinds of ideas. The comments focused on meeting design as well as on facility design. A number of problem areas focused on too much lecturing and not enough opportunity for participation, noting that in many groups the process is dominated by the leader, presenter, or one or a few members of the group. These authority figures influence the members' input and the objectivity of the data, with limited opportunity for interaction between the participants. If the participants are not going to interact, there seems questionable motivation for having a group meeting.

Physical features of the room were presented as problems: uncomfortable chairs, chairs too close together, poor arrangement to promote eye-to-eye contact, difficulties in hearing, poor audio/visual equipment, handout materials not reflecting the content the content of the preparation, the lack of relevance of the presented material to real work back home. Other physical problems included the difficulty of identifying rooms for breakout sessions, the tendency for the lecturer to present too much detail in the vugraph and read to the audience, the lack of entertainment and exciting activities to keep motivation up, inadequate restrooms and inadequate time, length, and frequency of breaks. The lack of clear agendas and clear conference outlines also were mentioned as problems, as well as the lack of common definition of terms or the assumption of common definitions when, in fact, there were multiple definitions. Appendix B lists the 63 problems presented by the participants.

Few existing conference centers have adequate breakout rooms for groups of thirty or more and the few centers that have breakout rooms have no flexibility in their size. This can be a problem when the large group breaks into smaller groups to work on sub-problems and the same numbers of the large group may not, for specific kinds of problems, go to each subgroup. That is, thirty to fifty may want to work on one problem, five on a second problem, etc. Open Space Technology, A User's Guide, by Harrison Owen (ISBN 0-961805-3-5), documents the advantage of letting participants for certain kinds of meetings choose the subgroup that they wish to go to (voting with their feet). Therefore, a learning center with flexible breakout room sizes would fit this structure best. 


\section{Features of a Team Learning Center}

This diverse set of individuals was then asked to describe what features a team learning center would have. A team learning center was described as a facility where approximately 100-200 people could come together in a common geography in which each member of the group had information and perspectives to contribute. A separate issue is meetings that are separated in time and space. Clearly these kinds of meetings are now technologically feasible and, in fact, are widely practiced. For certain groups, certain times, and certain topics meetings can be separated in time and space. For meetings with high emotional content, first-time meetings of groups, and groups that have not worked together previously, there appear to be strong drivers to have the group meet at the same location and at the same time. Sheep and many other animals are herding animals. Consider the example of the sheep being shown a video or hearing an audio of a herd. Would this produce the same degree of comfort as if the sheep were actually with the herd? The same herding instincts are operational in some people at some times and must be acknowledged by the designers of interactions. There are many deepseated human psychological reasons for meeting face to face that are not met by meeting through video and audio.

Therefore, the group was instructed to consider those meetings where large numbers of people come together to do work as a large group and then part of the time as subgroups. Again, GroupWare was used, with each participant having their own PC. In less than twenty minutes 130 ideas were generated and the participants were asked to stop generating ideas so that the ideas could be ranked. Participants, using a ranking tool of GroupWare, ranked the first 100 ideas in one set and the 30 ideas in a second set. The authors have reviewed these ideas and grouped them into three headings: Comments and Desires for the Physical Site, Comments and Desires of the Technology, and General Philosophical Observations. Appendix $C$ is a summary of all the comments.

\section{Desires for the Physical Site}

The comments of the research group indicated a desire for a facility sensitive to human needs and highly flexible in its structure. There was a desire, obviously, for smaller groups to meet within the context of a larger group with the ability to vary the coupling between the small groups and the larger group. That is, there is a desire from time to time to do work in groups of six to eight, but there also is synergy from that smaller group hearing and being aware of what is happening in other smaller groups. Therefore, a flexible meeting arrangement that can couple or decouple small groups would be desirable. It also is desirable that this flexibility allow for 
larger subgroups and subgroups of different sizes; that is, if 100 people come together, it may be desirable to have three subgroups of thirty, five subgroups of twenty, one of fifty, and five of ten, etc.

Several individuals indicated the desire to have the facility located in a setting where participants could get away from the machines and other people, walk, think, and be mentally and physically refreshed. There is a need for individualized lighting, temperature control, and adequate restroom facilities that could accommodate a short break by a large group. Unless there are adequate restroom facilities, a group of 100 people cannot take a ten-minute break.

There was a desire expressed for flexibility in access to the facility. That is, some individuals might like to work at different times; they would like the ability to work on computers individually in hotel rooms and easily bring that information into the conference room. Again stressing the need for flexibility in the way the facility is organized.

Overnight housing and ready availability of food is necessary for meetings extending longer than one day. The provisioning of some small internal rooms with music, appropriate settings, and features for comfort and reflection also were requested. There also was a suggestion that to increase the comfort of the attendees, that the center might provide a standard uniform of comfortable, slacks, tops, shoes or sandals. Dressing in something other than their own clothes might provide greater stimulation to think out of the box for some participants. It also eliminates some cultural differences, status symbols, power symbols, and might provide a more team-like environment. In describing the nearby woods, someone observed that the best sharing of ideas and brainstorming often occurs in relaxed, enjoyable human environments, like taking a walk by a lake or a hike, sitting in a comfortable restaurant sharing a meal, or going on an excursion. These settings are where much human creativity occurs and should be a part of any design intending to enhance creativity.

A clever suggestion was that the team should be on a raisable platform for visibility in reporting. Not observed, but obvious, is that lowering the table also could truncate excessively long reports. There was a desire for ease of movement between the groups and the ability to see 360 degrees from any position, a challenge to the design. There was an suggestion that the facility needs adequate exercise facilities to meet the needs of modern conference attendees. This is further acknowledgment that the center would recognize the whole human and all human needs. Conferences that start at 8:00 a.m. and run into the evening, with minimum or no time for participants to exercise an relax are not getting the maximum energy level and creativity from the participants. Designing in time for recreation, exercise, entertainment, casual, informal interactions keeps energy levels up, and promotes teaming, and provides a catalytic environment for creativity. 


\section{Desires of the Technology}

Most of the ideas provided centered on the technology support to the center. It was summarized perhaps best by the top ranked item: ease of interfaces between people and computers and people and people. The capability of electronically providing world-wide access to research materials, to other groups, to constituencies, and to audio and video materials clearly was a desire of the group and clearly within the constraints of current technology. The concept of electronic linking provides access not only to a world-wide spectrum of research materials but also provides the capability of communicating with one's colleagues and constituencies they are representing at the meeting is a powerful concept for cascading ideas and developing broadbased consensus over large groups scattered in time and space. The ready availability of multimedia technology to assist in the sharing and learning was noted by a number of the attendees. Many attendees pleaded for transparent technology and readily available training. There also was a desire for instant translation of foreign languages.

\section{General Philosophical Observations}

The third set of characteristics were a few comments that simply addressed philosophical approach. One observation was made that when physical interaction was necessary, the meeting should use the strength of that interaction. The tasks that should be worked by large groups should be only those tasks that have to worked by the large groups, joined at the same time and space. That is, the transmission of information by one individual to a hundred people does not require a hundred people to come together at one point in time. Solicitation of ideas from a hundred people on a controversial topic on which they need to be stimulated by one another to other points of view may and would be suitable justification for pulling the people together. The thought was added that one should integrate music and physical activities to assist in the sharing of ideas. The division of activities into entertainment, learning, conference presentations is probably archaic. All the activities should be focused on being entertaining and learning at the same time. Finally, the point was made that adequate time should be allowed for thorough discussion so that attendees do not leave with the feeling that the decision was made by the computer.

\section{Characteristics of the Center}

With this input, how might one begin to design a center begin to meet these needs? The design begins with seating. The chairs must be comfortable for sitting for long periods. You do not bring 100 people together, in general, for a short meeting. That means that chairs must be flexible: variable in height, a reclining back, varying tension in the reclining back, adjustable 
back angle and seat angle. Such chairs are now in use in some conference rooms. Such chairs are not stackable. While the chairs need casters for movement, being stackable should not be a design constraint.

Once the general dimensions of the chair are set, the facility scales itself as will be demonstrated. A comfortable chair is about $2-2.5 \mathrm{ft}$. by $2-2.5 \mathrm{ft}$. In order to use a simple design program, the following illustration (Figure $1^{*}$ ) will be used to represent the chair but is NOT intended to represent its actual appearance, only its size.
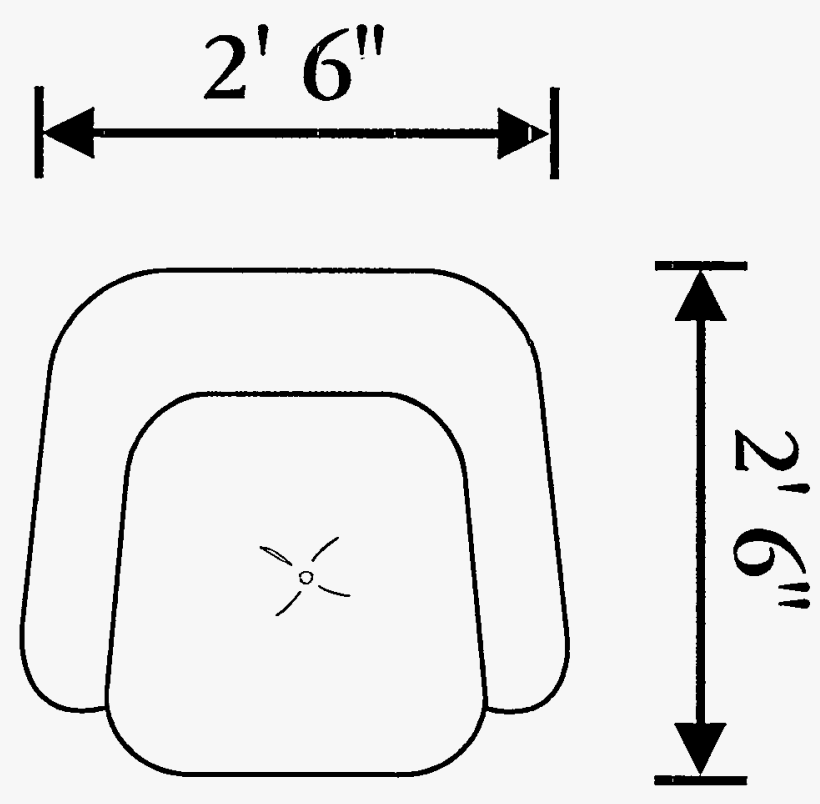

Figure 1. Chairs must be flexible, roomy and comfortable for long periods. This is a size illustration only.

If we assume that the unit size for a single table should accommodate a maximum of ten chairs, then the diameter of the table is set (Figure 2). The reader can make a different assumption and change the scale. For ten seats, the circumference should be $\sim 30$ feet, or a radius of 5 feet.

*Drawings in Figures 1-4 are not to scale but can be used as visualization aids. 


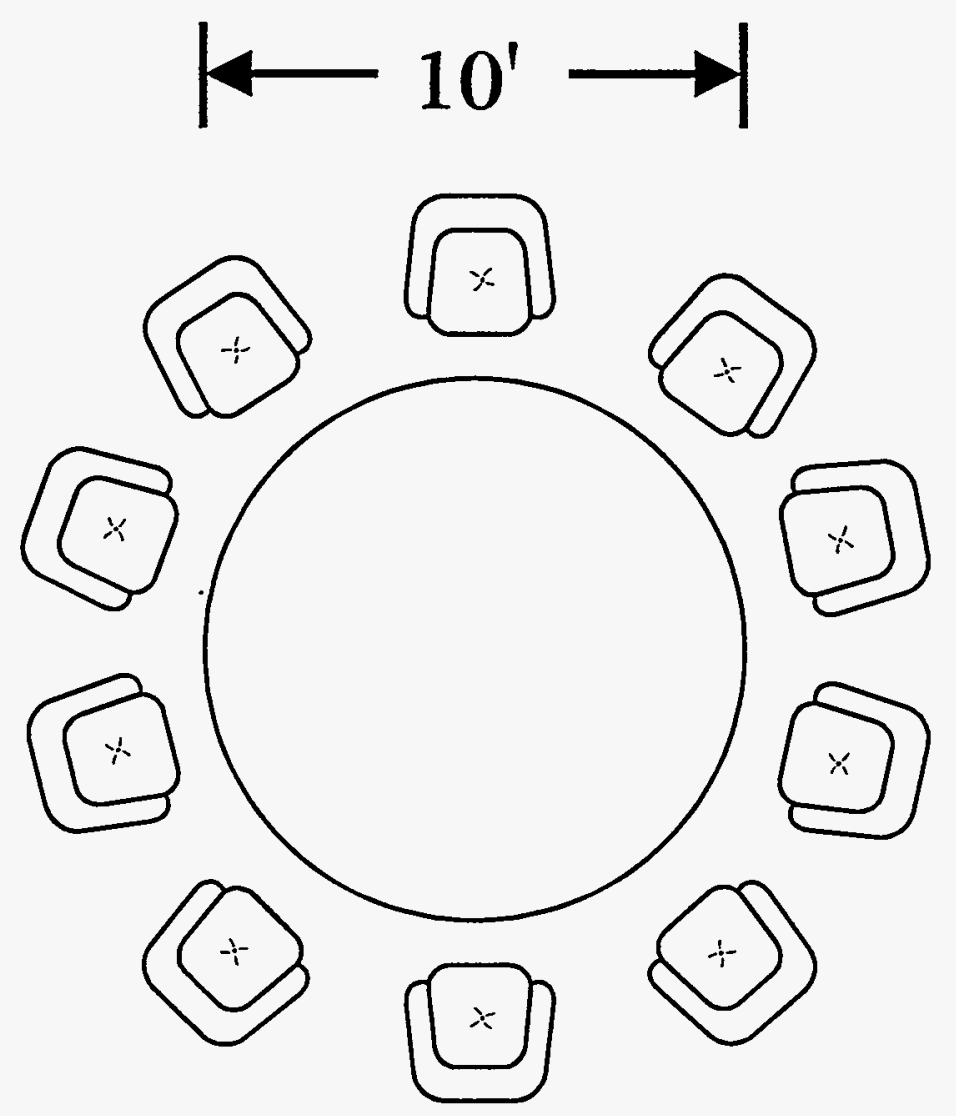

Figure 2. Small groups are planned for two to ten per unit, with the actual size determined by the facilitator or group. Units can be combined.

Now we assume a round, raised platform to be used by facilitator(s) in the center of a circle of tables with the capacity of ten sets each. The first circle would have a radius of 21 feet and accommodate fifteen tables, or fifty people (see Figure 3). The reasons for this choice will be clearer as the room design is described.

A second tier at a 40 -foot radius would accommodate an additional eleven tables for an additional capacity of 110 , or 160 total. If one provided sound partitions, that could roll along radii of the room from the outside wall to the center podium, one could quickly subdivide the room as shown into groups of two tables or larger, depending upon the need, and the partitions could provide partial or total isolation, as needed. 


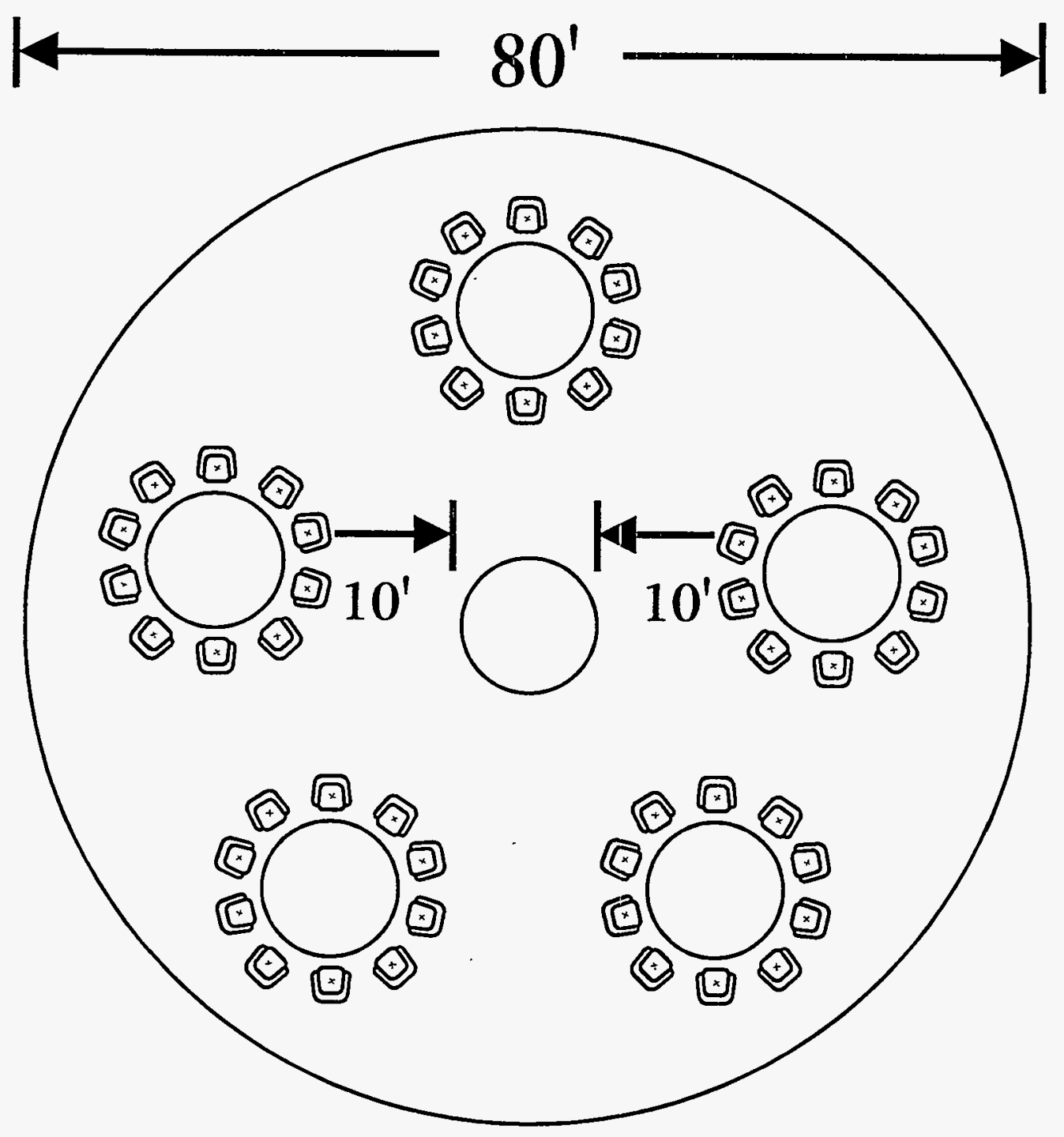

Figure 3. The center of the room is a raised, 10 -foot diameter platform surrounded by a circle of five of the tables (two-ten seats per table).

This then would provide a flexible room where large-group work and small-group work, with various sizes of small groups, could be accommodated with minimum disturbance of the participants.

There are a number of variations possible on this theme, but the key is a radially designed conference center with electronic control from the center (Figure 4). 


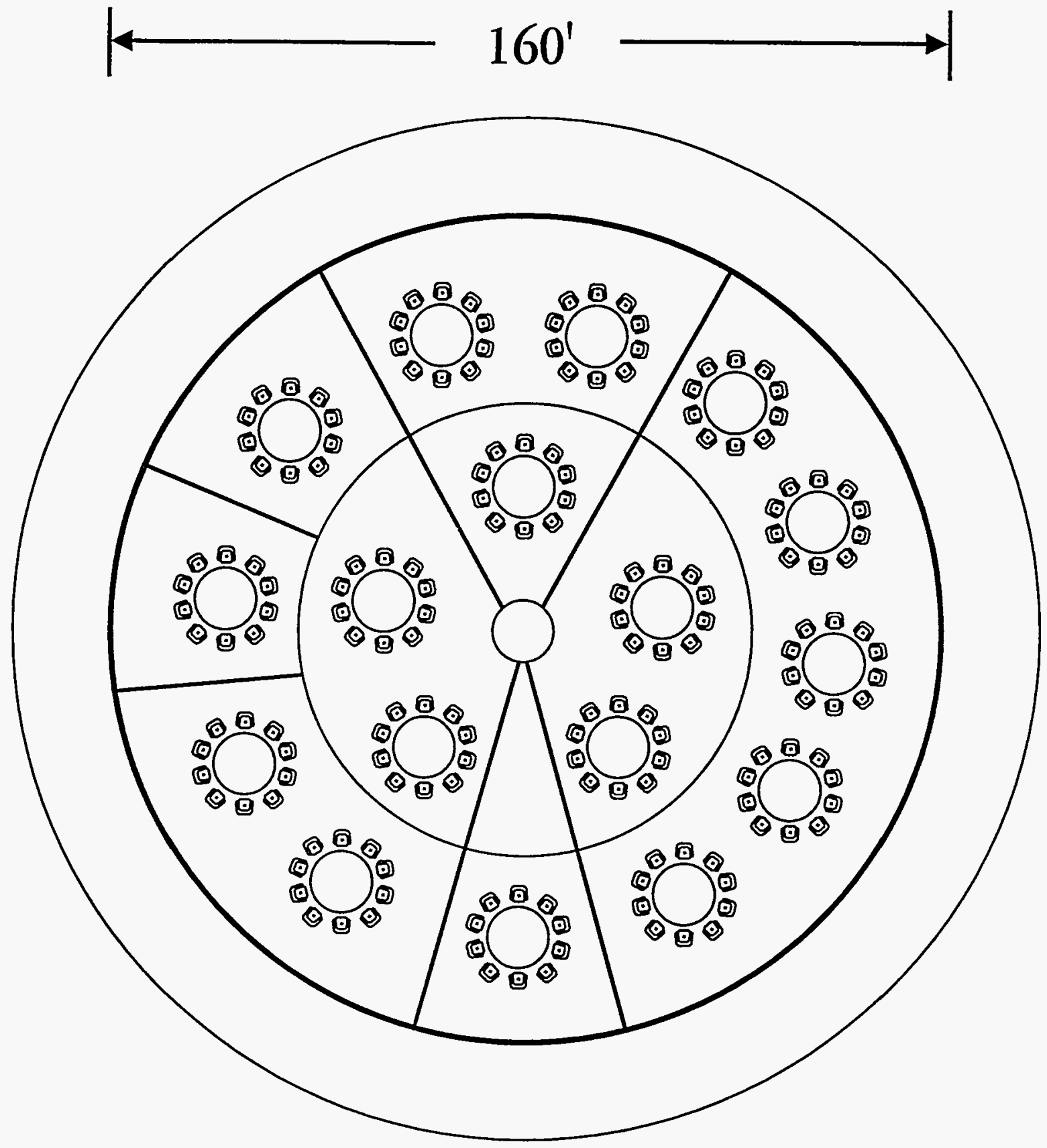

Figure 4. Another circle of eleven tables provides for a total capacity of 160 seats. Radial partitions provide the flexibility to divide into groups of various sizes quickly, and resize the room as issues or needs change.

Consider how different this is from conventional conference rooms--lecture halls have tiered chairs in semicircles focused on one person, clearly projecting the message that the wisdom in 
the room is at the center of the circles, not in the participants. It is almost impossible to do teamwork in such a lecture hall. A flat, open, large room, like a gymnasium floor or banquet room that hotels have, allows the placing of circular tables, but does not allow isolation from one another, nor any way to bring central focus easily for all of the tables. Even those hotel conference rooms that have sound partitions that roll at right angles require considerable difficulty to roll the walls out and can only be rolled to fixed partition sizes. The suggestion is that by placing these sound barriers on radii, they can be rolled out completely or partially. Any or all of them can be brought out, subdividing the room into different parts, different sizes, different sized subgroups, with a redividing of the room at any point during the day when it is desirable to do so. The facilitators standing in the center of the room could interact with any of the subgroups without having to move a great deal. By only partially bringing the radial partitions down, partial isolation can be obtained from one group to another where content and group dynamics made such a choice desirable. Outside of the conference room an additional circle should be located with small reading rooms, adequate restroom facilities, water fountains, access to food, coffee, etc. Finally, outside of the building could be walkways, trees and gardens to allow participants that desire it a retreat from the conference for some thinking time alone. An advantage would be to have other recreational facilities such as a golf course, ski hills located nearby to promote team recreational activities for team building, continuing the formal interaction and generation of ideas.

The authors intend to continue research on the number of questions raised so far by this investigation and hope to construct one or more pilot facilities of this design to collect data on its utility. 


\section{Appendix A}

\section{List of Attendees}

\section{New Mexico State University}

Danny Arnold, Dean, School of Business Administration and Economics

John Loveland, Professor, Department of Management

Arthur Whatley, Professor, Department of Management

Michael Manning, Associate Professor, Department of Management

Bonnie Daily, Assistant Professor, Department of Management

Ed Page, Graduate Assistant, Department of Management

Michael Morehead, Associate Dean, Department of Education

Nolan Gray, Coordinator, Learning Resources Center

Karen Wiburg, Assistant Professor, Department of Curriculum and Instruction

Eric Johnson, Associate Professor, Department of Electrical and Computer Instruction

John Bentley, Office of VP for Student Affairs

Pat Hynes, Project Director, New Mexico Space Grant

Douglas Gillon, Assistant Professor, Department of Psychology

Rod Merta, Assistant Professor, Department of Counseling and Educational Psychology

Steven Bernhardt, Associate Professor, Department of English

Thomas Cyrs, Professor, Department of Educational Management and Development

David Pengelley, Department of Mathematics

Celinda Levy, Assistant Professor, Department of Health Science

\section{Sandia National Laboratories}

Charles Tapp, Director of Quality Improvement

Ruth David, Director of Advanced Information Technology

Milton Clauser, Manager of Program Management Department

David Hasti, SNL/NMSU Partnership Office

Adrian Gurule, Quality Tools Department

\section{Other}

Fran Tapp, Parent; Officer, Parent Teachers Association 
(This page intentionally left blank) 


\section{Appendix B}

\section{List of Problems}

The participants listed the following items, along with the supporting comments; they did not rank-order these items.

\section{Lack of agenda organization}

\section{Uncomfortable seating}

Chairs too close together; poorly structured

Uncomfortable chairs make it hard to concentrate

\section{Too much lecturing, not enough opportunities for participation}

People don't come prepared to share best ideas

Not enough opportunities to brainstorm

People not encouraged to think outside of traditional paradigms

Structure is still a lecturer and listeners supported by room setup and schedule

\section{Lack of common definitions of terms}

Different definitions from different disciplines

\section{Wasted time}

Groups tend to be slow to get down to task or produce useful learning. It's difficult to keep commentary focused, side issues develop, and limits of attention interfere. In groups, individuals bring various agendas and various backgrounds, and the process of getting on the same "wavelength" can consume a lot of time and energy.

\section{Some people dominate}

\section{Disorganized}

\section{Prepared lectures not a good way for participants to learn}

Lack of visualization/connections among ideas

Too much too fast

Lack of coordinated handouts

People need to interact and input and the process track the dynamism 
9. Difficulty in being heard in large groups

10. No opportunity for interactions--leader/presenter lead discussion Too large a group

No opportunity to choose the session or emphasis you want

11. Hard to see overhead

12. Problem with horizontal communication

Hard to talk lying down

13. Only one person talks at a time

14. Presentation materials difficult to see

15. Lack of focus or organization

16. To much time spent on one topic

Not enough material for everyone to share

17. Authority figures in meetings inevitably influence members' input

18. Failure to establish effective communications among participants

19. Comfort, bad sound system, too warm/cold room, bad lighting Uncomfortable chairs, too much material - too little time

20. Hard to camouflage boredom

21. Difficulty in seeing all people in room

22. Individual group reporting to large group takes too long

23. Hard to get to presenter to talk about reaction

24. Handout materials did not reflect content of presentation Not related to meaningful situations for participants 
Not connection between conference and what follows

No commitment from administration that what is learned will be valued once the person gets back to work

25. No opportunity for interaction between participants

26. Meetings are usually poorly designed prior to the meeting

27. Lack of understanding of audience needs with respect to content level

28. Sleepy after lunch

29. Small group discussion is almost impossible

30. Difficulty in applying what is learned back at work

31. Hard to tap into the collective group wisdom

32. Inadequate breaks - need to stretch

33. Large groups have a difficult time of working from a consensus perspective

34. Distraction by beepers and telephones

35. One-shot in-services/training has almost no long-term effect What is presented may not be related to real problems at home Need a whole new design that integrates everyday work with training not just unrelated one-shot stuff Technology which could make information available unrelated to time and space is not utilized at conferences

36. Difficulty finding the rooms for the breakout sessions

37. Some participants are even stronger than the moderator/presenter

38. Some people do not contribute, loafers

39. Presenters assume knowledge not present in audience

40. Tendency to put too much detail on VG \& read to audience 
41. Sessions are either too short or too long Leader lectures without input from the audience Leader does not go with the flow

42. Purpose of most conferences does not seem to be learning Not enough material or supplies for all participants

43. Not enough entertainment, just boring stuff

44. Redundancy of ideas is not seen as positive

45. Too much breadth and not enough breadth on important items

46. 24

47. Aggressive participants overwhelm others; stifle conversation Moderator must manage interactions

48. No feedback within group activities

49. Not enough senses are involved

50. Unclear, unspecified meeting objectives are the norm for most meetings

51. Hard to concentrate when the topic/info stimulates other thoughts

52. Too much touchy feely, get to know you stuff

53. Lack of AV facilities for small group meetings

54. Participants don't get equal time to show off

55. Allows individuals to avoid participation

56. Too much time spent on uninteresting topics

57. Too few people actually attend meetings, out to golf

58. Restrooms always far away, mid-day breaks to short

59. Pre-coordinated content needed to reduce redundancy in workshops 
60. Interpersonal interactions interfere with learning

61. Conference outcomes are not agreed upon before - usually compiled/mailed by staff

62. Most people do not know adequate presentation skills

63. Not enough material and supplies

No connection between conference and follow-up at home 
(This page intentionally left blank)

B-6 


\section{Appendix C}

\section{Summary of Comments}

\section{Important Characteristics (Part 1)}

First, the participants developed a list of 130 characteristics, with some duplication, along with the supporting comments. Then the participants rated these characteristics in two groups. The first group of 100 characteristics is listed below in rated order, with the most important first, rather than in the order they were initially submitted.

1. Ease of interfaces between people and computers, and people and people

2. Reference materials available on demand.

Possibly access to on-line data bases.

3. Make sure that all technology can be interfaced.

4. Provide for electronic groupings not just physical groupings.

5. Multimedia presentation capability both large and small scale.

6. Interaction among small groups.

7. Modular design of the space so that it can be reconfigured rapidly.

8. Technology tools should include notebooks, drawing tools, calculators.

These tech tools should be intuitive and very easy to use including ability to sketch and project ideas, thinking and idea organizers that are non-linear.. like balloons for ideas that can be eerily clustered

Prefer laptop computers to large machines even think lab on a cart so the laptops can be easily moved as needed from group to group

9. Ability to connect via sight and sound to other locations via satellite.

10. Need an interactive environment with flexibility.

Smaller rooms with networked PCs and or laptops

Larger rooms with smaller interactive units--hand held keypads?

11. Small groups can meet within the context of a much larger group.

There is some synergy created from very large groups that are necessary to keep even though we might need to work in teams of 6 to 8 sending groups to breakout rooms would defeat this value of the very large group

12. State-of-the-art sound system with mikes for all participants (cordless).

13. Interconnectivity in the building and with the outside. 


\section{Mobile technology that allows for upgrading.}

Stay away from technology that is set in stone in the meeting rooms technology advances too quickly, ease flexibility of changing technology by allowing portability. This also allows flexibility of room use as technology may not be appropriate for all situations.

15. Truly interactive - between each other $\&$ external sources.

16. Make advanced presentation technology (i.e. multimedia development tools) available to everyone.

That will require some training.

17. Distance tech should be used so attendees can participate in agenda.

18. On-line capabilities-the ability for the people at the center to communicate with groups the represent who are not present.

19. Comfort and convenience.

20. Permit people to get away and think in private -- to explore ideas.

21. Recessed terminals or laptops that allow full view of others.

22. Make outside experts available electronically.

23. Utilize multimedia technology to assist in sharing of ideas.

24. Ergonomically designed chairs.

25. Use smart software to automatically group like topics.

The software should be able to look for common words and phrases and group those together without human intervention.

26. Ability to access information at the center at a later time;

i.e., notes from the sessions, etc.

27. Technology should be transparent.

28. Follow-on interactive participation on-line.

29. On-line access to "expert references."

Ability for individual to seek additional depth of information immediately, or "bookmark" a reference online for later perusal.

30. Allow for outside interaction through various forms of technology.

31. The facility should include tutorials on "how to work in teams."

32. Ability to directly interact with presentation materials;

e.g., hit ? when you want to interrupt with a question - speaker knows immediately. Enter question from keyboard - automatic capture of question and response. 
33. Quiet space and quiet time for people to go to be alone.

To meditate to reflect

34. When personal interaction is necessary, use its strength.

Have researchers involved in the design of the conference who understand how to potentiate the human interactions.

35. There needs to be a way for small groups to communicate with each other.

36. Instant translation of foreign languages.

37. Availability to display all data collected at one time.

Perhaps this would be shown on a large board or side of the building there is something about physically being able to see the "whole" of all the data before any reduction process takes place.

38. Lots of expert systems that provide instant additional information on any topic.

39. Facility be affordable.

40. Face-to-face interaction available at all times.

Wilderness course capabilities in conjunction with GDSS, multi-media, etc.

41. Room should be "in-the-round" to facilitate horizontal communication.

42. Face-to-face interactions even for people indifferent rooms (maybe via v...

43. Design principles associated with agenda setting, facilitation talents, action planning, strategic thinking, organizational/team learning are requisites for center work.

44. Connect and distribute the resources.

Tap into the network so the work/training/meeting can take amorphous shapes, so subgroupings can form, and so that learning is delivered just-in-time. You need to connect to information resources, meeting tools, and people who are not in the same place/same time.

45. External environment very attractive and accessible for reflection.

46. Small team tables should provide for facilitation.

47. The facility should provide for "comfort zones" for climate control.

48. Allow for various language needs.

49. Walking spaces for teams to walk together and create.

50. Envision a network of smaller TLCs.

Consider capacity of each about 50. Real-time networking to enable "simulcast" of materials, brainstorming, etc. Exchange views in series of smaller groups - better dynamics. Would need to ensure diversity in each group. 


\section{Capability for mentoring.}

Mentoring/shadowing. Lets say that a person was not clear on how to share--both verbally and how to use the technology a way to have an on-line- "wizard-like" interactive supportive entity that maintained anonymity but helped people express themselves

Yes--people want personal support, an on-line-live-help person. Take the idea for software company bulletin boards, where a rep of the company hangs out periodically to help out clients, but where anyone who arrives at the bulletin board can help anyone else who asks for help. These systems show how to take advantage of distributed expertise and the natural inclination and rewards of helping people.

52. Should support both short-term use and multiple-day use.

Consequently, cost of use for short-term people should not be a major constraint

53. Personal lighting each person's work area.

54. Ease of movement between groupings.

55. Focus on commonalities of the group instead of differences.

56. Individual walks away with annotated "transcript" of session.

Central capture of group-generated information; augmented with personal comments that are automatically merged at the appropriate points in the discussion--individuals walk away with full record.

57. Non-reflective lighting equally distributed throughout the work area.

58. Environmental control with access to outside view.

59. Technology-supported means for using work prior to conference at conference.

Work assigned so people do some pre-writing and organizing of information and this will already be online in a group database when people arrive.

60. Pilot testing of the facility be part of the design.

61. Integrate art, music, physical activities to assist in sharing ideas.

62. Build in translation/interpretation capability.

Captions for hearing impaired etc. Consider "NATO-style" translation capability to encourage global interactions.

\section{Relaxation/exercise/entertainment.}

Easy access to pleasant human environments for relaxation, recreation, exercise, entertainment, cultural events; this variety will stimulate the most creative impulses from participants.

\section{360 degree view from any position.}

Reference resources available on demand

65. Walk-around accessibility to the computer interfaces. 
66. Allow for thorough discussion of ideas.

Avoid feelings that a "computer" made the decision.

67. Some means to have separate environment controls (temperature).

68. Natural environment surrounding the center a must.

69. Think functionality.

Whiteboard, shared document production, simulated face-two-face through video windows, group facilitation software, archives, group chat/MOO, tete-a-tete, off- record conversation, email.

70. Facilities organized to allow time and space for individual thinking.

71. Audio system that lets people sample what different smaller groups are talking about.

72. Beverages (water) available that will not interfere with the equipment.

73. The physical dimensions of the center must be balanced with the best process dimensions of group dynamics. That is, the first principles of conferencing should be the driving values of the center.

74. Could we develop voice-activated ways of collecting information?

Some people still do not feel comfortable typing into a computer

75. Database of pictures and vocabulary terms to illuminate conversations needs to be available in all languages, including American Sign Language, and can also use audio.

76. Relaxation rooms--virtual reality???

77. Integrate virtual-reality technology.

78. Ability to access data previously collected that applies to current topic.

79. Need lots more space per person than typical.

80. Background music available by area if desired.

81. Presenters do not have to be in the same room as all participants.

82. Provide both access and non-access environments to reference resources.

People should be able to choose individual and group situations where they have access to reference materials, i.e., great library resources, whether paper or electronic, and also to "get away from the paraphernalia" to go somewhere where they are alone with only their own thoughts and whomever they may be with. Access to technology-free outdoors is crucial.

83. l'd like to have windows above the group work space.

84. The conference center if connected to a hotel could have computers in the rooms to enable participants to continue to work. 
85. Some part of the facility that is always open and has some good software for thinking and idea generation like Inspiration.

. This area also needs to provide Internet access to back home for all participants

86. Think network, not facility.

Must have direct access to Internet (T1 lines-coaxial cable)

Like the circle. Machines available next to table and talk space.

Availability of common and rich multimedia database at all times.

Don't build a building. Build a learning network. Build a client-server that can distribute group work resources to places they are needed. Dial into the net using Telnet and log on to a session with groupware.

87. Have stations available that meet the learning needs of participants.

88. Where the building would actually be located is important.

Should you have multi-day events, you may want overnight housing readily available. Of course, food services would be very much needed.

\section{Small groups should be able to "walk in the woods"!}

The best sharing of ideas and brainstorming often occur in relaxed, enjoyable human environments, like taking a walk by a lake, or a hike, or sitting in a comfortable restaurant sharing a meal, or going on an excursion. This is where a lot human creativity occurs between individuals. It should be part of any design intending creativity!

This is another reason not to bring people together physically. People can be comfortable at home or in their ergonomically adapted offices and can participate either synchronously or asynchronously, as they are comfortable and ready.

\section{Think rooms with music for reflection.}

91. Give people their own intelligent agents to help with specific needs.

Needs include format of information (visual, auditory, spatial, text, etc.), search for information, translation from one kind of jargon to another.

92. Tables should be on platforms that can be raised during reporting.

\section{Conference room requirements:}

1. 600 feet of work tables; 2 . two concentric circles with the inner circle facing the outer circle; 3 . carpeted; 4. chairs that swivel and have rollers; 5 . recessed monitors which allow participants to see over them; 6. keyboards at a comfortable level; 7. microphones and headsets to allow for in-seat breakout sessions; 8. presentations should take place on each individual monitor with a full-motion digital image of the speaker on each monitor when desired.

94. Some of the work spaces should be at standing height for working.

95. Soft drinks available at all times.

96. Air seats contoured to each individual participant.

97. Mediation

C-6 
98. Consider entire facility as a semi-circle rather than a circle.

Other features: raised central platform, tiered audience etc., could still be used. Concern re central figure having back to half of the audience.

99. Not everyone is in need of access to each type of technology to participate.

100. Perhaps a learning center uniform.

Comfortable, loose, unisex item with flat slippers to help each participant feel on same level with each other. Also, men don't like ties--women don't like high heels and girdles. Just the sheer comfort of this would make me more creative and productive.

1 Ease of interfaces between

Number of Votes in Each Rating

people and computers, and

$$
\begin{array}{rrrrrrrrrrrrr}
1 & 2 & 3 & 4 & 5 & 6 & 7 & 8 & 9 & 10 & \text { Mean } & \text { STD voters } \\
- & - & - & - & - & - & 1 & 3 & 3 & 5 & 9.00 & 1.04 & 12
\end{array}
$$

people and people

2 Reference materials available $\quad-\quad-\quad-1 \quad-\quad-2 \begin{array}{llllllll} & 2 & 4 & 5 & 8.53 & 1.64 & 15\end{array}$ on demand

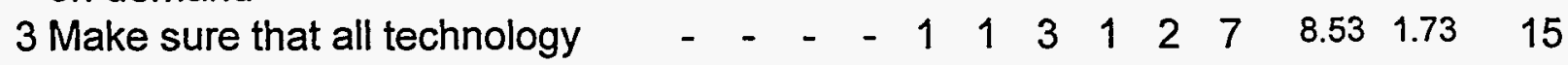

can be interfaced

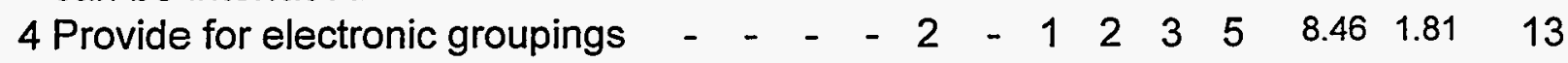
not just physical groupings

5 Multimedia presentation

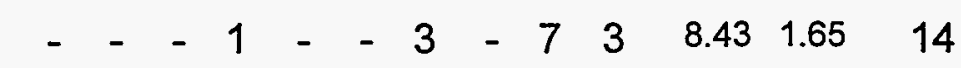
capability both large and small scale

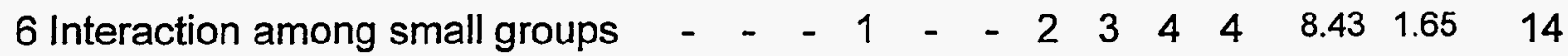

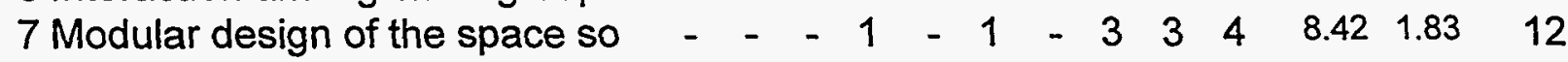
that it can be reconfigured rapidly

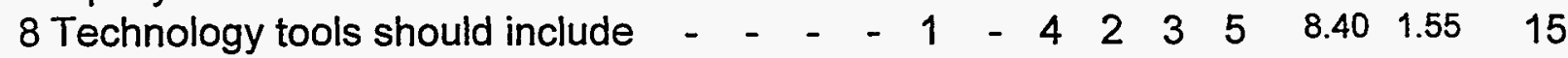
notebooks, drawing tools, calculators that...

9 Ability to connect via sight and $\quad-\quad-\quad-1 \quad-\quad-2444448.401 .59 \quad 15$ sound to other locations via satellite

10 Need an interactive environment with flexibility

11 Small groups can meet within the context of a much larger group

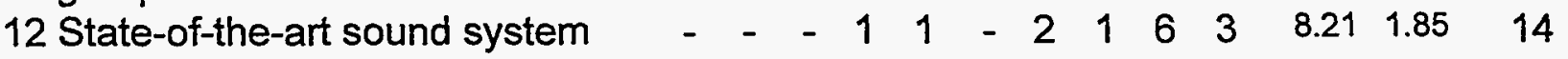
with mikes for all participants (cordless)

13 Interconnectivity in the building $\quad-\quad-1 \quad-1 \quad-2 \begin{array}{lllllll}3 & 3 & 5 & 8.20 & 2.04 & 15\end{array}$ and with the outside 
13 Interconnectivity in the building $-1-1-2335$
$-\quad-12-1235$

$8.20 \quad 2.04 \quad 15$ and with the outside

14 Mobile technology that allows for upgrading

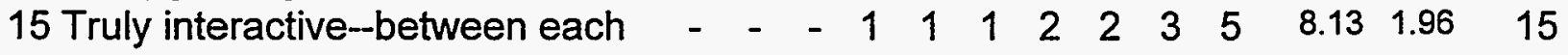
other \& external sources

16 Make advanced presentation technology (i.e., multimedia development tools)

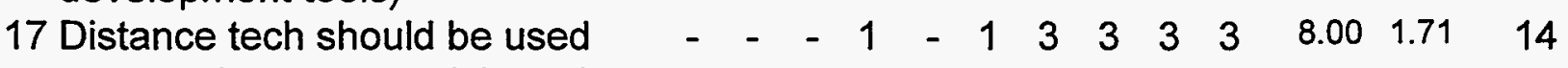
so attendees can participate in agenda

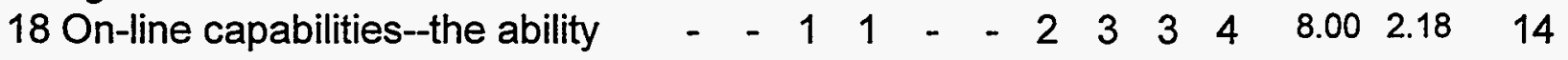
for the people at the center to...

19 Comfort and convenience

20 Permit people to get away and think in private--to explore ideas

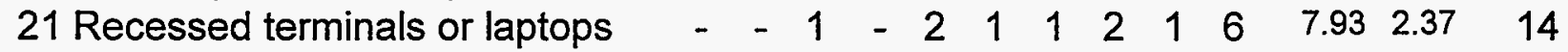
that allow full view of others

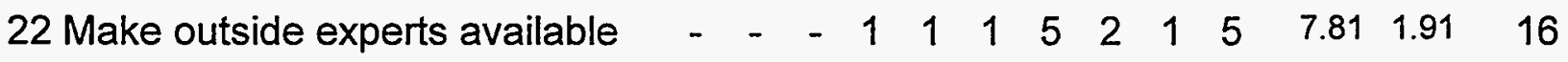
electronically

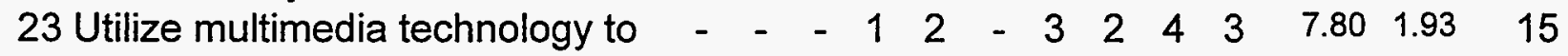
assist in sharing of ideas

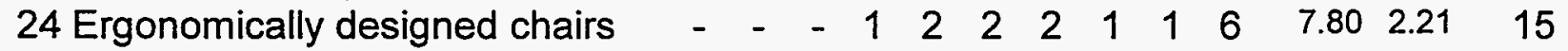

25 Use smart software to automatically group like topics

26 Ability to access information at the center at a later time

27 Technology should be transparent

28 Follow-on interactive participation on-line

29 On-line access to "expert references"

30 Allow for outside interaction through various forms of technology

31 The facility should include tutorials on "how to work in teams"

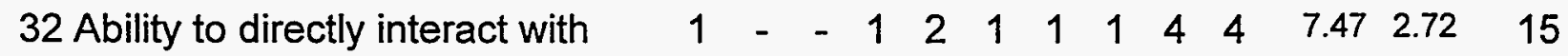
presentation materials.

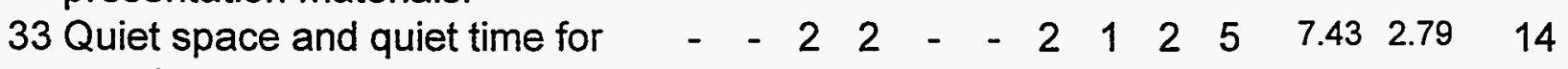
people to go to be alone 
34 When personal interaction is

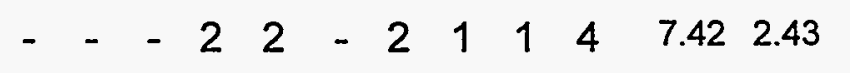

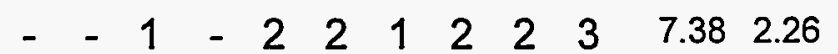
necessary, use its strength.

35 There needs to be a way for small groups to communicate with each other

36 Instant translation of foreign languages

37 Availability to display all data collected at one time

38 Lots of expert systems that

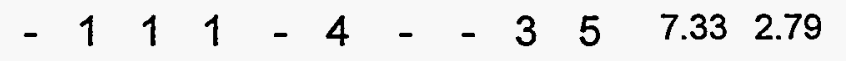

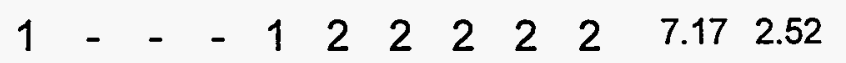

15

13 provide instant additional information

39 Facility be affordable [also see \#16, Part 2]

40 Face-to-face interaction available at all times

41 Room should be "in-the-round" to facilitate horizontal communications

42 Face-to-face interactions even $\begin{array}{llllllllllll}1 & -1 & - & - & 1 & 3 & 2 & 1 & 3 & 7.17 & 2.79\end{array}$

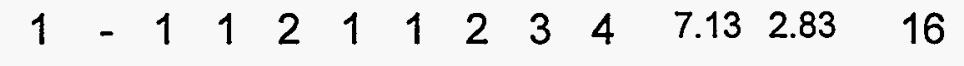

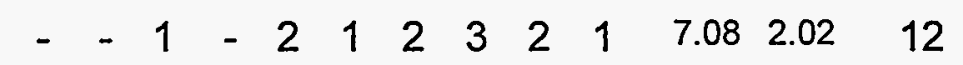
for people in different rooms

43 Design principles associated with agenda setting, facilitation talents

44 Connect and distribute the resources

45 External environment very attractive and accessible for reflection

46 Small team tables should provide for facilitation

47 The facility should provide for

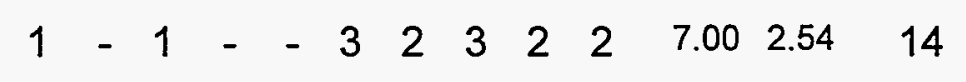

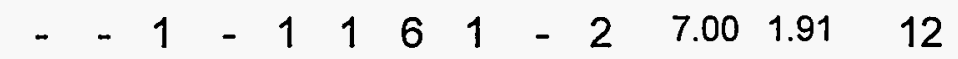
"comfort zones" for climate control

48 Allow for various language needs

49 Walking spaces for teams to walk together and create

50 Envision a network of smaller TLCs

51 Capability for mentoring

52 Should support both short-term use and multiple-day use

53 Personal lighting each person's

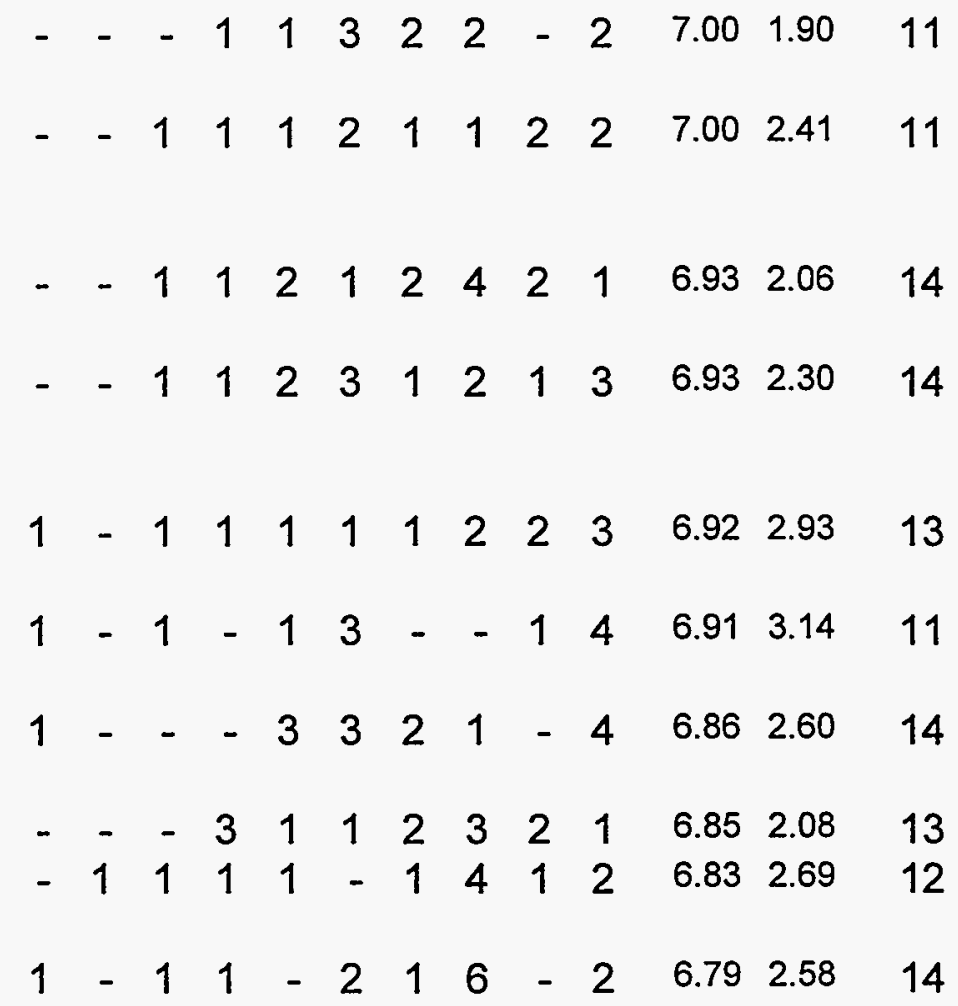
work area 
54 Ease of movement between

$$
11-\begin{array}{llllllllll}
1 & 1 & 2 & 1 & 5 & 3 & - & 6.71 & 2.52 & 14
\end{array}
$$

55 Focus on commonalities of the $\quad \begin{array}{lllllllllllll}1 & - & 1 & 1 & 1 & 1 & 2 & 3 & - & 3 & 6.69 & 2.81 & 13\end{array}$ group instead of differences

$\begin{array}{lllllllllllllll}56 & \text { Individual walks away with } & 1 & - & 1 & - & 1 & 1 & 2 & 4 & 1 & 1 & 6.67 & 2.57 & 12\end{array}$ annotated "transcript" of session

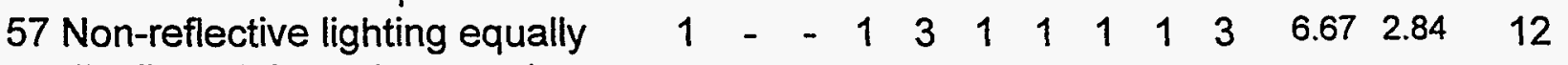
distributed throughout work area

58 Environmental control with access to outside view

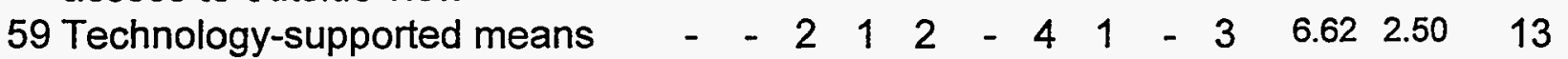
for using work prior to conference at conference

60 Pilot testing of the facility be part of the design

61 Integrate art, music, physical activities to assist in sharing ideas

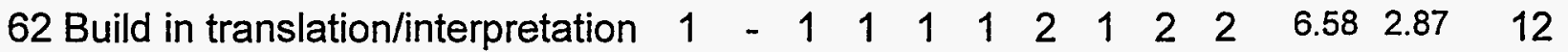
capability

63 Relaxation/exercise/ entertainment

64360 degree view from any position

65 Walk-around accessibility to the computer interfaces

66 Allow for thorough discussion of $\quad-\quad \begin{array}{lllllllllll} & - & 3 & - & 2 & 3 & 1 & - & 2 & 6.33 & 2.31\end{array}$ ideas

67 Some means to have separate environment controls (temperature)

68 Natural environment surrounding the center a must

69 Think functionality

70 Facilities organized to allow time and space for individual thinking

71 Audio system that lets people sample what different smaller groups are talking about

72 Beverages (water) available that will not interfere with the equipment 
73 The physical dimensions of the

$$
\begin{array}{llllllllllll}
- & - & 1 & 1 & 2 & 1 & 2 & 1 & - & 1 & 6.11 & 2.15 \\
1 & 1 & 1 & - & - & 4 & 3 & - & 2 & 1 & 6.08 & 2.69 \\
- & - & - & 3 & 2 & 2 & 4 & - & - & 1 & 6.00 & 1.76
\end{array}
$$
center must be balanced with the best process

74 Could we develop voiceactivated ways of collecting information

75 Database of pictures and vocabulary terms to illuminate conversations

76 Relaxation rooms--virtual reality???

77 Integrate virtual-reality technology

78 Ability to access data previously collected that applies to current

79 Need lots more space per person than typical

80 Background music available by area if desired

81 Presenters do not have to be in $\quad-\quad \begin{array}{lllllllll} & - & 3 & 3 & 3 & 2 & - & 5.83 & 1.53\end{array}$ the same room as all participants

82 Provide both access and non-

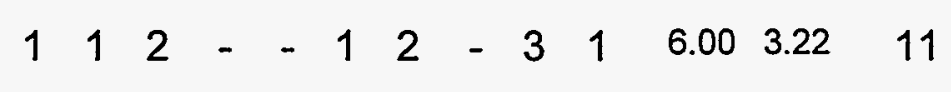

$\begin{array}{lllllllllllll}1 & 1 & 1 & 1 & 3 & 1 & 4 & 1 & 2 & 1 & 5.94 & 2.57 & 16\end{array}$

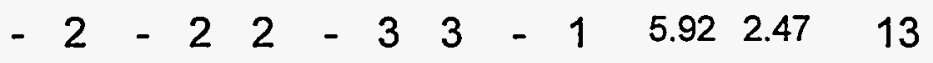
$\begin{array}{lllllllllllll}1 & - & 2 & 2 & 3 & 2 & 1 & - & 1 & 3 & 5.87 & 2.83 & 15\end{array}$ $\begin{array}{lllllllllllll}1 & 1 & 1 & 2 & 2 & - & - & 3 & 2 & 1 & 5.85 & 2.97 & 13\end{array}$ access environments to reference resources

83 I'd like to have windows above the group work space

84 The conference center, if connected to a hotel, could have computers in the rooms to...

85 Some part of the facility that is always open and has some good software

86 Think network, not facility

87 Have stations available that meet the learning needs of participants

88 Where the building would actually be located is important

89 Small groups should be able to "walk in the woods"!

90 Think rooms with music for $\begin{array}{rrrrrrrrrrrr}- & 1 & 3 & 2 & - & 2 & - & - & 1 & 3 & 5.83 & 3.13 \\ 1 & 1 & - & 1 & 2 & 2 & 1 & 1 & - & 2 & 5.82 & 2.89\end{array}$ 12 $\begin{array}{lllllllllllll}1 & 1 & - & 1 & 2 & 2 & 1 & 1 & - & 2 & 5.82 & 2.89 & 11\end{array}$ $\begin{array}{lllllllllllll}1 & 1 & 1 & - & 2 & 2 & 2 & 1 & - & 2 & 5.83 & 2.86 & 12\end{array}$ 12

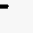




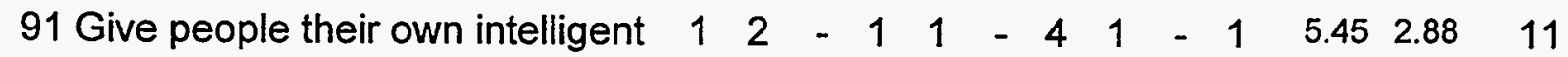
agents to help with specific needs

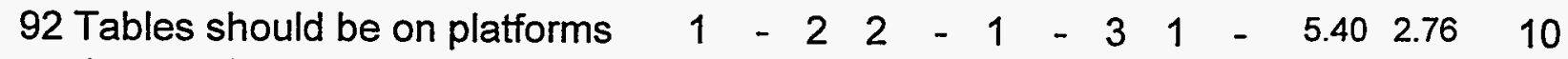
that can be raised during reporting

93 Conference room requirements $1 \begin{array}{lllllllllllll}1 & - & 2 & 2 & - & 1 & 2 & - & 1 & 1 & 5.40 & 2.88 & 10\end{array}$

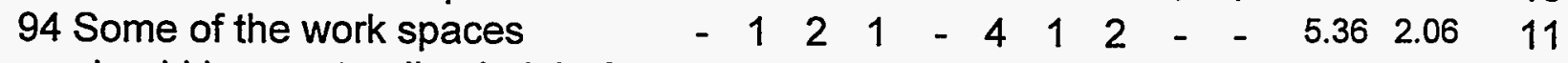
should be an standing height for working

95 Soft drinks available at all times

96 Air seats contoured to each individual participant

97 Mediation

98 Consider entire facility as a semi-circle rather than a circle

99 Not everyone is in need of access to each type of technology to participate

100 Perhaps a learning center uniform

$\begin{array}{rrrrrrrrrrrrr}3 & 2 & - & - & 1 & - & 2 & 1 & 2 & 1 & 5.17 & 3.56 & 12 \\ 2 & 2 & 1 & 2 & - & 1 & - & 1 & - & 3 & 5.08 & 3.58 & 12 \\ 2 & - & 2 & 2 & 1 & - & - & 1 & 1 & 1 & 4.80 & 3.19 & 10 \\ 1 & 2 & - & 2 & 2 & 2 & 2 & - & - & - & 4.45 & 2.07 & 11 \\ 1 & - & 2 & 2 & 1 & 2 & 1 & - & - & - & 4.33 & 1.87 & 9 \\ 10 & 1 & - & 1 & - & - & - & - & - & 1 & 2.00 & 2.55 & 13\end{array}$




\section{Appendix C}

\section{Summary of Comments}

\section{Important Characteristics (Part 2)}

First, the participants developed a list of 130 characteristics, with some duplication, along with the supporting comments. Then the participants rated these characteristics in two groups. The second group of 30 characteristics is listed below in rated order, with the most important first, rather than in the order they were initially submitted.

1. Adaptive human/machine interfaces.

Ability to configure interface to optimize ability of individual to effectively interact (voice recognition, synthesis, graphics, text, video, keyboard, mouse, ... ).

2. Ease of presentation by anyone at any location of the room.

3. Ability to interact with comparable facilities world-wide.

Establish "regional" TLCs that are networked. Efficient means to collect diverse opinions, extract regional influences etc. (Ideally, this would be global in extent.)

4. Fresh, clean air and temperature control.

5. This meeting house should have two-way audio/video communication with outside world--both ways.

6. Tech tools need to include CD-ROM and video capability.

7. Easy and fast access to "necessary" comfort stations.

8. Energy-efficient, environmentally friendly built design and systems.

9. Loose/tight properties; i.e., table configuration, fixed chairs flexible.

10. Ability to communicate with different break-away groups without having to physically move.

11. Keep the circle idea, it works. May want multiple circles as well.

12. Personal workspace should include capacity to create privacy.

13. A staff that can address and identify the needs of each group.

14. Flexible schedules for work so everyone doesn't have to do work at same time and place. Can have some agreed upon times for all to meet.

15. Design the building to allow natural light and solar energy efficiency.

16. (Addition to \#85) for most groups.

17. Multiple rooms for groups of two hundred to meet at once. 
18. A great variety of working environments:

Restaurants, living quarters, exercise facilities, the great outdoors, wilderness, lounges, ... (use your imagination). The best ideas often emerge when consciously/actively doing something else! Allow mixing and regrouping of individuals so that people end up communicating face to face with a real variety of others through time.

19. Staff "advertising" specialist to oversee "packaging."

Pre-review of all presentation materials to assure that they engage the audience.

20. Portable small laptop capable of downloading via infrared any place in the center.

Large electronic chalkboard where ideas that have been gathered by groups can be displayed.

21. Allow for question to be framed immediately and early response available.

22. Color-coded/coordinated areas.

23. Use natural light in high windows on sides of round facility.

24. Hydraulic lifts to raise or lower platforms or entire floor areas.

25. Chalkboards!!! (sorry if this seems old-fashioned!).

26. Child care on premises.

27. Talk to the folks in Las Vegas--they know how to keep people involved.

28. Tape recording systems to completely record everything.

Multi-city synchronized meetings, with AV and computers networked.

Why do we need tape recorders when we have multimedia computers?

29. All tables must be round.

30. Eject buttons to exit the meeting from the contoured air seats.

Perhaps the group could come to consensus on who should be ejected, and press a "group button" to evict one or more individuals.

That is not to exclude an individual from pressing his or her own button.

Or perhaps, two consenting adults could eject together.

There also could be warning buzzers attached to seats, three buzzes you're out. 
Number of Votes in Each Rating

1 Adaptive human/machine

$\begin{array}{llllllllllll}1 & 2 & 3 & 4 & 5 & 6 & 7 & 8 & 9 & 10 & \text { Mean STD voters }\end{array}$ interfaces

2 Ease of presentation by anyone at any location of the room

3 Ability to interact with

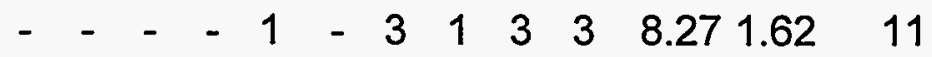
comparable facilities world-wide

4 Fresh, clean air and temperature control

5 This meeting house should have two-way audio/video communication

6 Tech tools need to include CD- $\quad-\quad-\quad-\quad-\quad \begin{array}{lllllllll}1 & 1 & 3 & 3 & 1 & 2 & 7.73 & 1.56 & 11\end{array}$ ROM and video capability

7 Easy and fast access to "necessary" comfort stations

8 Energy efficient, environmentally friendly built design and systems

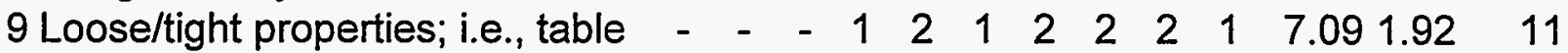
configuration fixed chairs

10 Ability to communicate with different break-away groups without...

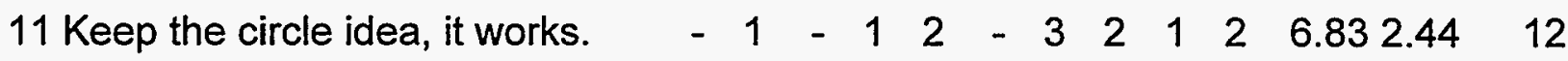
May want multiple circles as well

12 Personal workspace should include capacity to create privacy

13 A staff that can address and identify the needs of each group

14 Flexible schedules for work so $\quad-\quad \begin{array}{lllllllllll}2 & 2 & - & - & 3 & 1 & 1 & 2 & 6.55 & 2.66 & 11\end{array}$ everyone doesn't have to do work at same [time?]

15 Design the building to allow natural light and solar energy efficiency

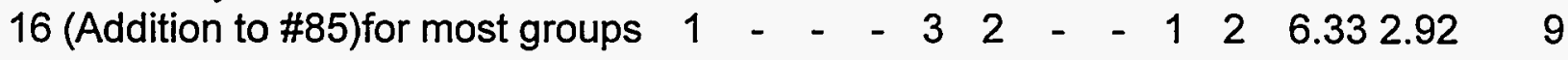
[now \#39 in Part 1]

17 Multiple rooms for groups of two $-\quad-\quad-142-\quad-3-6.301 .9510$ hundred to meet at once

18 A great variety of working environments: 
18 A great variety of working

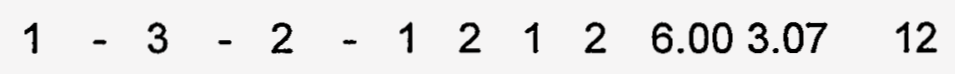
environments:

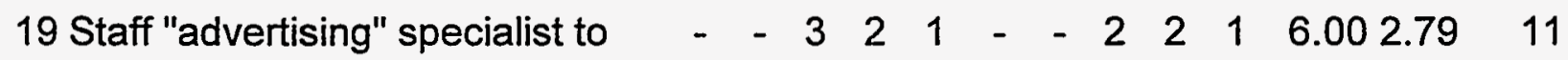
oversee "packaging"

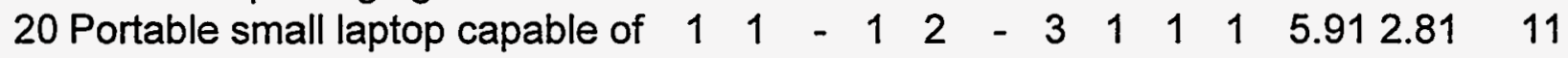
downloading via infrared any place

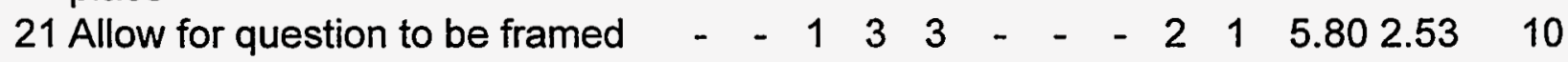
immediately and early response available

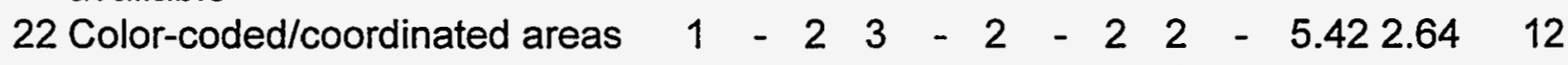

23 Use natural light in high

$\begin{array}{llllllllllll}- & - & 4 & 1 & - & 1 & 1 & 1 & 1 & 5.36 & 2.66 & 11\end{array}$ windows on sides of round facility

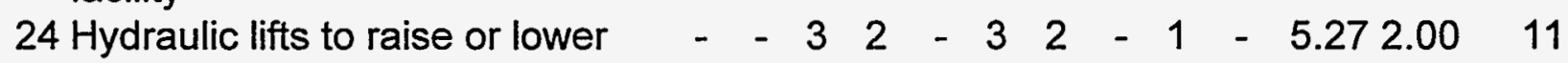
platforms or entire floor areas

25 Chalkboards!!! (sorry if this seems old-fashioned!)

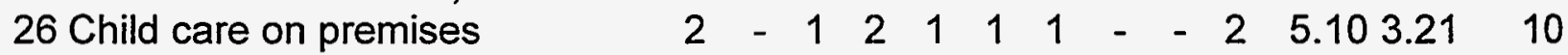

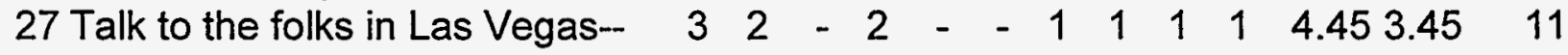
they know how to keep people involved

28 Tape recording systems to completely record everything

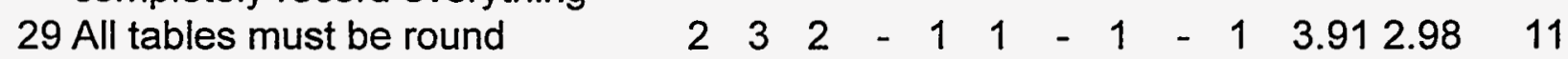

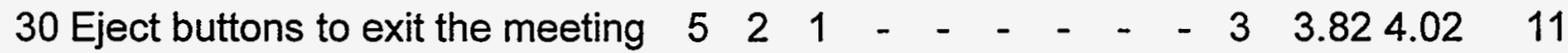
from the contoured air seats 


\section{DISTRIBUTION}

3 ea New Mexico State University

Box 30001

Las Cruces, NM 88003-0001

Attn: John Loveland, Dept. 3DJ

Arthur Whatley, Dept. 3DJ

Bonnie Daily, Dept. 3DJ

1 ea Danny Arnold, Dept. 3AD

Michael Manning, Dept. 3DJ

Ed Page, Dept. 3DJ

Michael Morehead, Dept. 3AC

Nolan Gray, Dept. 3CUR

Karen Wiburg, Dept. 3CUR

Eric Johnson, Dept. 3-0

John Bentley, Dept. 3923

Pat Hynes, Dept. 3-0

Douglas Gillon, Dept. 3452

Rod Merta, Dept. 3CEP

Steven Bernhardt, Dept. 3E

Tom Cyrs, Dept. 3N

David Pengelley, Dept. 3MB

Celinda Levy, Dept. 3446

1 ea Fran Tapp

8731 Tierra Alegre NE

Albuquerque, NM 87122

1 ea MS 1435 Ruth David, 1090

0318 Milton Clauser, 1401

0753 David Hasti, 6200

0103 Virgil Dugan, 12100

10 ea $\quad 1369$ Charles Tapp, 12900

1 ea 1369 Kenneth Hanks, 12900

1369 Karen Higgins, 12900

1369 Karen Pound, 12900

1361 Maureen Baca, 12909

1359 David Bushmire, 12911

1359 Adrian Gurule, 12911

1357 Amado Trujillo, 12913

9018 Central Technical Files, 8523-2

5 ea $\quad 0899$ Technical Library, 13414

1 ea 0619 Print Media, 12615

2 ea 0100 Document Processing, 7613-2

For DOE/OSTI

Dist-1 
(This page intentionally left blank)

Dist-2 